Journal of Extension Education

Vol. 28 No. 3, 2016

DOI:https: / /doi.org/10.26725/JEE.2016.3.28.5719-5722

\title{
Role of Women in Ethno Veterinary Practices
}

\author{
S.Vigil Anbiah ${ }^{1}$ and R.Vijayalakshmi ${ }^{2}$
}

\begin{abstract}
A study was conducted to assess the involvement of women in various components of ethno veterinary practices in Cuddalore and Nagapattinam districts of Tamil Nadu state. It was found that assisting the traditional practitioner was the most preferred activity where women involved with much enthusiasm in both Cuddalore and Nagapattinam Districts.
\end{abstract}

Keywords: Ethno Veterinary, Women, Livestock, India

Medicinal plants, since time immemorial, have been used in virtually all cultures as a source of medicine. The use of traditional medicine and medicinal plants in most developing countries, as a normative basis for the maintenance of good health, has been widely observed (UNESCO, 1996). Ethno-veterinary medicine (EVM) is a system that is based on folk beliefs, traditional knowledge, skills, methods and practices pertaining to the healthcare of animals that are rarely codified and transmitted orally from generation to generation (MathiasMundy \& McCorkle, 1989; Tabuti et al, 2003). This knowledge is based on close observation of animals and/or the oral transmission of experience from one generation to the next. It is perceived as simple, cost-effective, environment friendly, contextually appropriate and culture-based (Kolawale et al, 2007)

Women possess indigenous knowledge to treat diseases using medicinal plantcompounds, manipulative techniques, herd management as well as socio-cultural procedures. Involvement of women in small holder livestock system would improve the livelihood standards by more profit oriented activities. However the participation of women in ethno-veterinary practices is decreasing. Hence a study was conducted to assess the role of women in ethno veterinary practices among the livestock farmers of Cuddalore and Nagapattinam Districts of Tamil Nadu.

\section{METHODOLOGY}

The study was conducted in

1.Head-In-Charge, Central Animal House, Rajah Muthiah Medical College, Annamalai University and 2. Associate Professor and Head, Department of Animal Husbandry, Annamalai University. Annamalai Nagar - 608002 , Tamil Nadu, India.

Received : 17-07-2017; Accepted : 01-08-2017 
Cuddalore and Nagapattinam districts of Tamil Nadu state. These districts were identified by the planning commission of India as disadvantaged districts of Tamil Nadu and the farmers are engaged in low cost livestock rearing activities. Hence a low cost treatment facility to livestock farmers will be of much use and therefore an initiative to assess the role of women in ethno veterinary practices was taken up to know their respective roles in handling medicinal plants and herbs. A sample of 150 respondents in each of the districts was finalised for the data collection. To understand the role of women in Ethno Veterinary Practices, the respondents were given a set of questions in the regional language designed for this purpose. A well structured and pretested interview schedule was used for the collection of data.

\section{FINDINGS AND DISCUSSION}

The details of participation of women in various Ethno Veterinary Practices in Cuddalore \& Nagapattinam Districts are furnished in Table 1.

Table 1.

\section{Role of Women in Ethno Veterinary Practices in Cuddalore \& Nagapattinam Districts}

$(n=150)$

\begin{tabular}{|c|c|c|c|c|c|}
\hline \multirow{3}{*}{$\begin{array}{l}\text { S1. } \\
\text { No. }\end{array}$} & \multirow{3}{*}{ Activities } & \multicolumn{4}{|c|}{ District } \\
\hline & & \multicolumn{2}{|c|}{ Cuddalore } & \multicolumn{2}{|c|}{ Nagapattinam } \\
\hline & & No. & $\%$ & No. & $\%$ \\
\hline 1. & Assisting the traditional practitioners & 99 & 66.00 & 101 & 67.30 \\
\hline 2. & Preparation of herbal extract & 40 & 26.70 & 34 & 22.70 \\
\hline 3. & Marketing of poly herbal medicines & 06 & 4.00 & 09 & 6.00 \\
\hline 4. & Feeding poly herbal extract to animals & 04 & 2.70 & 06 & 4.00 \\
\hline 5. & Gathering medicinal plants & 01 & 0.60 & 0 & 0.00 \\
\hline & Total & 150 & 100 & 150 & 100 \\
\hline
\end{tabular}

From Table 1, it is understood that nearly two-thirds of women in both the districts $166.00 \%$ in Cuddalore district and $67.30 \%$ in Nagapattinam District) were actively involved in assisting the traditional practitioners in treating the animals. Assistance to traditional practitioners is the most preferred activity of women because of their knowledge reinforcement and learning opportunities to prepare and market herbal preparations. By this, women get a chance to know about the ethnoveterinary practices. The traditional healers also expect the active assistance of the owners of the herds while treating 
the animals. About one-fourth of the women respondents $(26.70 \%$ and $22.70 \%$ respectively from Cuddalore and Nagapattinam districts) played a very significant role in the preparation of herbal extract for treating the animals. In indigenous treatment women prepared the herbal extract under the guidance and supervision of indigenous practitioners.

Marketing of poly herbal medicine for domestic livestock is done by a very few respondents. (4.00\% in Cuddalore district and $6.00 \%$ in Nagapattinam District). As more number of modern (allopathy) veterinary clinics are established in these districts the marketing of poly-herbal extract does not remain a lucrative enterprise. Hence very less number of women are involved in it.

Gathering of medicinal plants in the nearby forest areas, bushes, meadows etc were usually done by women in earlier days. But at present gathering of medicinal plants is a hectic task which could not be accomplished by women work force. It requires enormous trekking in high altitude ranges to gather medicinal plants. Women did not show interest possibly due to their family responsibilities. Also it provides them very poor revenue. Hence women respondents had almost stopped this practice.

In general, people prefer to get treatment for their livestock in modern veterinary dispensaries instituted by the government where free services are offered. Hence the number of ethno veterinary practitioners is decreasing and women also play very little role in ethno-veterinary treatment. However considering the significance of ethno veterinary medicines it is high time to document these practices and preserve the wealth of the knowledge of the indigenous veterinary practices.

It is concluded that ethnoveterinary practices is traditional knowledge which is based on close observation of animals and oral transmission of management as well as treatment experience from one generation to the other. Though it is perceived as simple, cost-effective and eco friendly, the role of women in this activity brings rural sustainable livelihood with low external input for livestock rearing. Though there are certain demerits in the involvement of women in terms of their family commitments, their association with the traditional practitioners in the preparation of herbal formulations would give a sustainable income to their families. This trend was observed in the respondents interviewed in both the Cuddalore and Nagapattinam Districts of Tamil Nadu.

\section{REFERENCES}

Kolawole, O.D., Okorie. V.O., Ogidiowa. M.T., \& Adeogun M.O. (2007). Ethno-veterinary practices amongst smallholder farmers in Ekiti State, Nigeria. African Journal of Traditional, Complementary and Alternative Medicine. 4,434-442 
Mundy Mathias, E. \& McCorkle C. M. (1989). Ethnoveterinary Medicine: An Annotated Bibliography, Bibliographies in Technology and Social Change. Technology and Social change Program, Series No 6, Iowa State University.

Tabuti, J.R.S., Dhillion, S.S. \& Lye, K.A. (2003). Ethno veterinary medicine for cattle (Bos indicus) in Bulamogi county Uganda: plant species and mode of use. Journal of Ethnopharmacology, 88:279-286.

UNESCO (1996). Culture and Health, Orientation Texts - World Decade for Cultural Development 1988 1997, Document CLT/DEC/PRO - 1996, Paris, France. 